\title{
Amadeus
} International Multidisciplinary Journal IISSN 2525-8281

DOI: 10.14295/aimj.v4i7.83

\section{Child Maltreatment: Brief Communication}

Amanda Plácido da Silva

Macêdo

Monnic Maria Lóssio Rocha

Maia $^{l}$

Izadora de Sousa Pereiral,

Thânia Maria Rodrigues

Figueiredo ${ }^{1}$

Modesto Leite Rolim Neto
Abstract: Child maltreatment has serious consequences, including increasing an individual's risk of physical and mental health problems across their life course. Objective: Here we show that there is an important public health message to focus, not only on approaches that prevent or detect childhood maltreatment, but also to explore methods of prevention and detection of mental ill health. Results: The study Childhood maltreatment and adult suicidality: a comprehensive systematic review with meta-analysis (2019) showed that all different types of childhood maltreatment including sexual abuse [odds ratio (OR) 3.17, 95\% confidence interval (CI) 2.76-3.64], physical abuse (OR 2.52, 95\% CI 2.09-3.04) and emotional abuse (OR 2.49, 95\% CI 1.64-3.77) were associated with two- to three-fold increased risk for suicide attempts. Conclusion: It is important to highlight emotional violence may actually be more powerful than physical and sexual abuse in its impact on adolescent suicide behaviors in low- and middle-income countries.

Keywords: Child Maltreatment; Mental Health; Prevention.

\section{Maltrato Infantil: Comunicación Breve}

\begin{abstract}
Resumen: el maltrato infantil tiene graves consecuencias, incluido el aumento del riesgo de un individuo de problemas de salud física y mental a lo largo de su vida. Objetivo: Aquí mostramos que hay un importante mensaje de salud pública para enfocar, no solo en los enfoques que previenen o detectan el maltrato infantil, sino también para explorar métodos de prevención y detección de enfermedades mentales. Resultados: El estudio Maltrato infantil y suicidio en adultos: una revisión sistemática integral con metaanálisis (2019) mostró que todos los diferentes tipos de maltrato infantil, incluido el abuso sexual [odds ratio (OR) 3.17, intervalo de confianza (IC) del 95\% 2.76-3.64 ], el abuso físico (OR 2.52, IC 95\% 2.09-3.04) y el abuso emocional (OR 2.49, IC 95\% 1.64-3.77) se asociaron con un riesgo de dos a tres veces mayor de intentos de suicidio. Conclusión: es importante resaltar que la violencia emocional en realidad puede ser más poderosa que el abuso físico y sexual en su impacto en los comportamientos suicidas de adolescentes en países de bajos y medianos ingresos.
\end{abstract}

Palabras clave: Maltrato infantil; Salud mental; Prevención.

\footnotetext{
${ }^{1}$ Federal University of Cariri - UFCA - Ceará, Brazil.

${ }^{2}$ Federal University of Cariri - UFCA - Ceará, Brazil. Corresponding author: modestorolim@ yahoo.com.br. 


\section{Introduction}

Child maltreatment has serious and lifelong consequences, including increasing an individual's risk of physical and mental health problems across their life course. Although estimates vary, globally, as many as a quarter of adults report physical abuse in childhood, and one-fifth of women and one in thirteen men report childhood sexual abuse (The Lancet Psychiatry, 2019). Adversities in childhood along with genetic or environmental vulnerabilities resulting from maternal mental health issues also contribute to young people's mental health outcomes, suggesting a role for broader social supports and early intervention services in addition to targeted mental health (Maclean, Sims and O'Donnell, 2019).

There is an important public health message to focus, not only on approaches that prevent or detect childhood maltreatment, but also to explore methods of prevention and detection of mental ill health in those who have experienced childhood maltreatment (Health Europa, 2019). Childhood maltreatment has an effect on emotional intelligence through its influence on social support, which affects the development and degree of mental symptoms (Zhao et al, 2019). Children who do not have supportive families or who blame themselves for the abuse or violence are more likely to have serious mental health problems (American Academy of Child \& Adolescent Psychiatry, 2019).

While physical abuse is shocking due to the marks it leaves, not all signs of child abuse are as obvious. Ignoring children's needs, putting them in unsupervised, dangerous situations, exposing them to sexual situations, or making them feel worthless or stupid are also forms of child abuse and neglect - and they can leave deep, lasting scars on kids (HelpGuide, 2019). Due to the multifactorial contributors and variable individual responses to child abuse and neglect experiences, individual presentations are highly variable and affected by the developmental stage of the child. Addressing the effects of child abuse and neglect at earlier developmental stages improves outcomes. Unaddressed effects of child abuse and neglect can have long-lasting consequences, resulting in a lifetime of mental and medical problems, with significant public health implications. Identifying and addressing deficits in the child or caregiving system could mitigate the risk of abuse or neglect being perpetuated, including to future offspring (Johns Hopkins , 2017). 
In this situational framework, childhood maltreatment increases the risk of suicide attempts in the general population, possibly having similar effects among patients with major depressive disorder (MDD). The few studies that have address this association have been restricted to specific populations (e.g. treatment-resistant depression, personality disorders) and have rarely taken sex into account (Golderg et al, 2019).

All types of childhood abuse are associated with increased risk for suicide attempts and suicidal ideation in adults independent of demographic, clinical and methodological variations across the studies (The Guardian, 2019). The analysis of 68 studies by psychologists at the University of Manchester and University of South Wales revealed that suicide attempts were: Three times more likely for people who experienced sexual abuse as a child; Two and a half times more likely for people who experienced physical abuse as a child; Two and a half times more likely for people who experienced emotional abuse or neglect as a child (Science Daily, 2019).

The study Childhood maltreatment and adult suicidality: a comprehensive systematic review with meta-analysis (Angelakis, Gillespie and Panagioti, 2019) showed that all different types of childhood maltreatment including sexual abuse [odds ratio (OR) 3.17, 95\% confidence interval (CI) 2.76-3.64], physical abuse (OR 2.52, 95\% CI 2.093.04 ) and emotional abuse (OR 2.49, 95\% CI 1.64-3.77) were associated with two- to three-fold increased risk for suicide attempts. Similar results were found for the association between childhood maltreatment and suicidal ideation. Complex childhood abuse was associated with a particularly high risk for suicide attempts in adults (OR 5.18, 95\% CI 2.52-10.63).

Currently the role of various neurotransmitters such as serotonin and dopamine affected by Child sexual abuse (CSA) are discussed. Serotonin abnormalities have been reported in various studies among participants exposed to CSA. Structures such as the prefrontal cortex, superior temporal gyrus, corpus callosum, parietal lobes, hippocampus, and cerebellum all demonstrate volumetric and structural changes in response to the trauma of CSA. Neurocognitive studies demonstrate memory and spatial awareness as well as decrements in general cognitive performance and memory when compared to normal individuals. The hypothalamic-pituitary-adrenal axis has also been implicated in CSA, and there is an alteration in corticotropin-releasing hormone response due to the continuous cumulative trauma of CSA (Shrivastava et al, 2017). 
Recent research has revealed that early life trauma (ELS) results in a cascade of neurobiological changes associated with cognitive deficits in adulthood that vary according to the type of trauma experienced (Gould_et al, 2012). The scientific evidence underlines that deficits in social cognitive function are a hallmark feature of major psychiatric disorders resulting in impaired social and occupational functioning, specifically with regard to emotion recognition and regulation, theory of mind (the ability to attribute mental states to oneself and others), attributional style, and social perception. Traumatic childhood experiences - such as emotional and physical abuse and neglect, early loss of caregivers, and insecure attachment styles - are frequently reported as high as 85 percent of patients with various psychiatric disorders (EurekAlert, 2018).

In this context it is important to highlight emotional violence may actually be more powerful than physical and sexual abuse in its impact on adolescent suicide behaviors in low- and middle-income countries. The analysis suggests that mental health practitioners should offer suicide prevention programs to those with a history of emotional abuse (Futurity, 2019).

\section{Acknowledgements}

The authors' thank Research Group: Suicidology-Federal University of Ceará UFC and National Council for Scientific and Technological Development-CNPq - body linked to the Ministry of Science, Technology and Scientific Writing Lab, Medicine School - Federal University of Cariri - UFCA

\section{References}

The Lancet Psychiatry. (2019). Child maltreatment and mental health. Retrieved from: https://www.thelancet.com/journals/lanpsy/article/PIIS2215-0366(19)30370-0/fulltext

Maclean ,MJ; Sims, SA; O'Donnell,M. (2019). Role of pre-existing adversity and child maltreatment on mental health outcomes for children involved in child protection: population-based data linkage study. BMJ Open 2019;9:e029675. Retrieved from: https://bmjopen.bmj.com/content/bmjopen/9/7/e029675.full.pdf 
Health Europa. (2019). Abused children four times more likely to develop mental illness. Retrieved from: https://www.healtheuropa.eu/abused-children-mental-illness-936902/93690/

Zhao, J; Peng, X; Chao, X, Xiang, Y. (2019). Childhood Maltreatment Influences Mental Symptoms: The Mediating Roles of Emotional Intelligence and Social Support. Front. Psychiatry, Retrieved from: https://doi.org/10.3389/fpsyt.2019.00415

American Academy of Child \& Adolescent Psychiatry. (2019). Trauma and Child Abuse Resource Center. Retrieved from: https://www.aacap.org/AACAP/Families_ and_Youth/Resource_Centers/Child_Abuse_Resource_Center/Home.aspx

HelpGuide. (2019).Child Abuse and Neglect. Retrieved from: https://www.helpguide.org/ articles/abuse/child-abuse-and-neglect.htm

Johns Hopkins (2019). Johns Psychiatry Guide, 2017. Retrieved from: https://www.hopkinsguides.com/hopkins/view/Johns_Hopkins_Psychiatry_Guide/787122/ all/Abuse_and_Neglect

Golderg, X; Serra-Blasco, M; Vicent-Gil, M; Aguilar, E; Ros, L; Arias, B;Courtet, P; Palao, D; Cardoner, N. (2019). Childhood maltreatment and risk for suicide attempts in major depression: a sex-specific approiach. Eur J Psychotraumatol; 10(1): 1603557. Retrieved from: https://www.ncbi.nlm.nih.gov/pmc/articles/PMC6507860/

The Guardian. (2019). Childhood abuse increases risk of adult suicide, finds research. Retrieved from: https://www.theguardian.com/society/2019/jan/09/childhood-abuseincreases-risk-of-adult-suicide-finds-research

Science Daily. (2019). Child abuse linked to risk of suicide in later life. Retrieved from: https://www.sciencedaily.com/releases/2019/01/190109192533.htm

Angelakis, I; Gillespie, ML; Panagioti, M. (2019). Childhood maltreatment and adult suicidality: a comprehensive systematic review with meta-analysis, Psychological Medicine, 49(7):. 1057-1078. Retrieved from: https:/www.cambridge.org/core/services/ aop-cambridge-core/content/view/043CB9ABD6 1C68B00C4F72EFE02B9A17/S0033291 718003823a.pdf/childhood_maltreatment_and_adult_suicidality_a_comprehensive_system atic_review_with_metaanalysis.pdf.

Shrivastava, A K;Karia, , Sonavane, SS; De Sousa, AA. (2017). Ind Psychiatry J, 26:4-12. Retrieved from: http://www.industrialpsychiatry.org/article.asp?issn=09726748 ; year $=2017$; volume $=26$; issue $=1$; page $=4$; epage $=12$; aulast $=$ Shrivastava .

Gould F, Clarke J, Heim C, Harvey PD, Majer M, Nemeroff CB. (2012). The effects of child abuse and neglect on cognitive functioning in adulthood. J Psychiatr Res. 2012 Apr;46(4):500-6. Retrieved from: https://www.ncbi.nlm.nih.gov/pubmed/ 22336639?dopt=Abstract.

EurekAlert. (2018). Childhood trauma linked to impaired social cognition later in life for patients with major psychiatric disorders. Retrieved from: https://www.eurekalert.org/pub_releases/2018-09/e-ct1091218.php 
Futurity. (2019). Emotional violence in childhood linked to thoughts of suicide. Retrieved from: https://www.futurity.org/thoughts-of-suicide-emotional-violence-2087722-2/

\section{How to cite this article (APA format):}

Macêdo, Amanda Plácido da Silv; Maia, Monnic Maria Lóssio Rocha; Pereira, Izadora de Sousa; Figueiredo, Thânia Maria Rodrigues; Rolim Neto, Modesto Leite (2019). Child Maltreatment: Brief Communication. Am. In. Mult. J., October. (7) 4, 105-110.

Received: 09/12/2019

Accepted: 10/10/2019 